\title{
EFEKTIVITAS PENDIDIKAN KESEHATAN DENGAN MEDIA VIDEO UNTUK MENINGKATKAN SIKAP DAN NIAT PENGGUNAAN AKDR
}

\author{
Dwi Kartikawati ${ }^{1}$, Wahyu Pujiastuti ${ }^{2}$, Masini $^{3}$, Siti Rofi'ah $^{4}$ \\ 1,2,3,4 Program Studi Kebidanan Magelang, Poltekkes Kemenkes Semarang, Indonesia
}

\begin{abstract}
Family planning is an effort to create a quality of family by regulating the birth of children, the ideal distance and age of childbirth, and regulating pregnancy. One of the contraceptives that are less attractive to couples of childbearing age is the Alat KontrasepsiDalam Rahim (AKDR). Health education with video media can be done as an effort to increase the use of AKDR contraception. Theory of Planned Behavior states that a behavior begins with the formation of attitudes and intentions. This study used an quasi experimental study with non equivalent control group design on attitude variables and static group comparison on intention variables. Data analysis used paired t test on attitude and chi square on intention. The results of the study that health education with video media effectively increases attitudes in the used of $A K D R$ with $p$ value $=0.00$ ( $p$ value $<0.005$ ) with video media more effective 4.75 higher than leaflet media, while health education with video media was not effective in increasing the intention to used an AKDR with $p$ value $=0.269$.
\end{abstract}

Keywords: Video Media; Attitude; Intent; AKDR 


\section{PENDAHULUAN}

Penduduk merupakan titik sentral dalam pembangunan berkelanjutan, yaitu pembangunan terencana di segala bidang untuk menciptakan perbandingan ideal antara perkembangan kependudukan dengan daya dukung dan daya tampung lingkungan serta memenuhi kebutuhan generasi sekarang tanpa harus mengurangi kemampuan dan kebutuhan generasi mendatang. Dalam mewujudkan pembangunan berkelanjutan dibutuhkan penduduk berkualitas. Penduduk yang berkualitas dibentuk dari keluarga berkualitas yang dilakukan dengan mengendalikan angka kelahiran, menurunkan angka kematian dan mengarahkan mobilitas penduduk (BKKBN, 2018).

\section{Keluarga Berencana} merupakan upaya untuk mewujudkan keluarga yang berkualitas dengan cara mengatur kelahiran anak, jarak dan usia ideal melahirkan, serta mengatur kehamilan (Presiden RI, 2014). Pemerintah telah menyediakan kontrasepsi non MKJP/Metode Kontrasepsi Jangka Panjang (pil, suntik, kondom) dan kontrasepsi MKJP (AKDR, AKBK, MOW, dan MOP) untuk mengendalikan kehamilan. Angka drop out metode MKJP (AKBK dan AKDR) lebih rendah dibandingkan metode non MKJP (pil dan suntikan) hal ini dikarenakan jangka waktu penggunaan MKJP yang relatif cukup panjang yaitu 3 tahun Alat Kontrasepsi
Bawah Kulit (AKBK) dan 10 tahun (AKDR). (Kemenkes RI, 2013)

Semua alat kontrasepsi pada dasarnya efektif, namun berdasarkan pertimbangan efek samping serta kelebihan dari penggunaan setiap kontrasepsi, maka AKDR merupakan metode MKJP yang paling sedikit menimbulkan keluhan dibandingkan dengan kontrasepsi yang lain (Kementrian Kesehatan Republik Indonesia, 2013). Keuntungan penggunaan kontrasepsi AKDR antara lain tidak perlu setiap kali mengingat tanggal untuk melakukan kunjungan ulang, tidak ada efek samping hormonal, dapat dipasang kapan saja, kesuburan dapat segera kembali setelah kontrasepsi dilepas, dan tidak membutuhkan tindakan operasi.

Data Badan Kependudukan dan Keluarga Berencana Nasional (BKKBN) pada tahun 2016 menunjukkan bahwa di Indonesia, cakupan peserta akseptor KB aktif Metode Jangka Panjang yang meliputi AKDR sebanyak 10,61 \% dari 25,99\% pengguna MKJP. Tahun 2017 di Provinsi Jawa Tengah, pengguna kontrasepsi AKDR 7,23 \%, dari $19,88 \%$ pengguna MKJP (BKKBN, 2018).

Tahun 2017 di Kabupaten Temanggung, dari 47,8 \% penggunaan alat kontrasepsi MKJP, metode AKBK menempati peringkat tertinggi yaitu dengan presentase $\quad 27,8 \%$, sedangkan penggunaan kontrasepsi AKDR mencapai 13,9 \%. Puskesmas Tembarak menempati peringkat terendah dalam penggunaan $\mathrm{KB}$ 
AKDR yaitu sebesar 7,1\%, AKBK merupakan metode yang paling diminati yaitu sebanyak 33,6\% dari 44,5 \% pengguna MKJP (Dinas Kesehatan Kabupaten Temanggung, 2017).

Berdasarkan data tersebut dapat diketahui bahwa kontrasepsi AKDR kurang diminati pasangan usia subur. Hal tersebut disebabkan adanya beberapa faktor internal yang berupa pengalaman, takut terhadap efek samping, pengetahuan atau pemahaman yang salah tentang AKDR, pendidikan Pasangan Usia Subur (PUS) yang rendah, malu dan risih, adanya kondisi tertentu yang merupakan kontraindikasi AKDR, dan persepsi tentang AKDR. Faktor eksternal berupa prosedur pemasangan AKDR yang rumit, pengaruh dan pengalaman akseptor AKDR lainnya, sosial, budaya, ekonomi, dan pekerjaan (Marmi, 2016)

Hasil studi pendahuluan yang telah dilakukan di Puskesmas Tembarak, alasan dari 20 orang tidak memilih KB AKDR yaitu 15 orang yang merasa takut saat pemasangan, 10 orang merasa malu, 3 orang merasa tidak tahu tentang AKDR (hanya mengetahui bahwa AKDR merupakan jenis $\mathrm{KB}$ ), 3 orang percaya bahwa AKDR mudah lepas sendiri dan 4 orang kurang mendapatkan dukungan dari suami. Bidan puskesmas dan bidan desa telah memberikan pendidikan kesehatan berupa penyuluhan kelompok (posyandu, kelas ibu hamil, dan PKK) dan pemberian pendidikan kesehatan secara mandiri kepada ibu post partum. Metode yang digunakan

dengan

ceramah, menggunakan media berupa leaflet dan lembar balik.

Penggunaan media pendidikan kesehatan dapat didasarkan pada kerucut pengalaman Edgar Dale yang menyebutkan bahwa proses pendidikan kesehatan dengan melibatkan lebih banyak indera akan lebih mudah diterima dan diingat oleh sasaran pendidikan. Media leaflet merupakan media visual yang hanya melibatkan indra penglihatan, sedangkan media video merupakan media audiovisual yang melibatkan indra pendengaran dan penglihatan (Suiraoka and Supariasa, 2012).

Media sangat penting digunakan dalam melakukan pendidikan kesehatan dalam rangka perubahan perilaku. Terdapat berbagai macam teori yang dapat digunakan dalam merubah perilaku, salah satunya yaitu Teori Tindakan Beralasan (Theory of Planned Behavior/ TPB). Theory of Planned Behavior (TPB) pertama kali dicetuskan oleh Ajzen menyebutkan bahwa keyakinan akan membentuk sikap, kemudian niat dan perilaku. Keyakinan bahwa proses pemasangan AKDR yang menakutkan dan memalukan, AKDR dapat keluar dengan sendirinya yang akan mempengaruhi sikap dan niat dalam penggunaan AKDR (Ajzen, 2006).

Sikap akan terbentuk berdasarkan pengetahuan yang diperoleh dari suatu pendidikan kesehatan. Pendidikan kesehatan akan mempengaruhi perilaku. Perilaku ini dibagi menjadi 3 tingkatan yaitu 
pengetahuan, sikap dan tindakan. Sehingga pemberian pendidikan kesehatan akan mempengaruhi pengetahuan, pengetahuan akan mempengaruhi sikap dan sikap akan mempengaruhi tindakan (Notoatmodjo, 2012). Berdasarkan latar belakang tersebut peneliti ingin meneliti tentang efektivitas pendidikan kesehatan dengan media video untuk meningkatkan sikap dan niat dalam penggunaan AKDR.

\section{METODOLOGI PENELITIAN}

\section{Penelitian ini menggunakan studi quasy eksperimental dengan non equivalent control group design pada variabel sikap dan static group comparison pada variabel niat, menggunakan pendekatan waktu prospektif. Penelitian dilakukan di kecamatan Tembarak kabupaten Temanggung pada bulan Maret} 2019.

Populasi dalam penelitian ini adalah seluruh ibu nifas yang ada di Puskesmas Tembarak sejumlah 41 orang. Teknik pengambilan sampel pada penelitian ini adalah simple random sampling dengan penghitungan sampel menggunakan rumus Slovin sehingga diperoleh 38 responden. Pengambilan sampel pada penelitian ini dengan menetapkan kriteria inklusi agar dapat mewakili populasi yaitu lbu yang belum pernah menggunakan KB AKDR, belum berniat untuk menggunakan AKDR, pendidikan SMP/SMA, usia 15-49 tahun, lbu dalam kondisi sehat, ada ditempat saat penelitian serta bersedia menjadi responden. Adapun kriteria eksklusinya adalah lbu dengan kontraindikasi penggunaan AKDR (riwayat penyakit radang panggul dan mengalami perdarahan pervagina yang belum jelas penyebabnya). Sampel yang memenuhi kriteria pada penelitian ini sebanyak 38 orang yang dibagi menjadi dua kelompok. Kelompok perlakuan sebanyak 19 orang diberikan intervensi pendidikan kesehatan menggunakan media video dengan menggunakan LCD selama 30 menit, sedangkan kelompok kontrol sebanyak 19 orang diberikan intervensi pendidikan kesehatan menggunakan media leaflet. Analisa data menggunakan paired test pada sikap dan chi square pada niat.

\section{HASIL PENELITIAN DAN BAHASAN}

Hasil dari analisis data diketahui bahwa skor terendah sebelum diberi pendidikan kesehatan dengan media video yaitu 8 dan dengan media leaflet yaitu 9 , dengan sebagian besar besar responden yaitu $94,7 \%$ pada media leaflet dan $57,9 \%$ pada media video beranggapan bahwa AKDR akan mengganggu hubungan seksual, 94,7\% pada media video dan laflet merasa malu saat pemasangan AKDR dan $94,7 \%$ pada media leaflet dan $78,9 \%$ pada media video takut saat dimasukkan alat. Pada proses pelepasan alat, seluruh responden beranggapan bahwa pelepasan alat tidak dilakukan secara kasar. Hal ini 
ditunjukkan dari jawaban pada pertanyaan tentang tentang cara pelepasan AKDR responden yang menjawab benar ada 19 orang (100\%). Rata-rata, sikap responden sebelum diberi pendidikan kesehatan dengan media video yaitu 13,68 dan 12,94 pada media leaflet.

Sikap seseorang terhadap suatu hal dapat dipengaruhi oleh beberapa faktor, diantaranya yaitu pengalaman pribadi, pengaruh orang lain yang dianggap penting, kebudayaan, media massa, lembaga pendidikan dan lembaga agama, dan pengaruh faktor emosional (Lestari, 2015). Kekhawatiran responden terhadap mitos AKDR yang dapat mengganggu hubungan seksual, malu saat pemasangan AKDR dan takut saat dimasukkan alat tidak disebabkan karena pengalaman pribadi, namun bisa terjadi karena faktor sikap yang lain karena responden yang diambil dalam penelitian ini merupakan responden yang belum pernah menggunakan AKDR. Selain itu, menurut penelitian (Febrianti, 2018) bahwa pengguna AKDR Post Placenta dipengaruhi oleh tingkat pengetahuan dan pendidikan ibu.

Setelah diberi pendidikan kesehatan dengan media video dan leaflet terjadi perubahan sikap yang bervariasi pada setiap responden. Skor sikap terendah pada media video yaitu 16 dan pada media leaflet sebesar 14. Rata-rata sikap pada media video yaitu 22,31 dan 18,63 pada media leaflet. Setelah diberi pendidikan kesehatan, masih banyak responden yang merasa malu saat pemasangan AKDR yaitu 89,5\% pada kelompok media leaflet dan 57,9\% pada kelompok media video.

Pemberian pendidikan kesehatan merupakan suatu upaya atau kegiatan untuk mempengaruhi orang agar ia atau mereka berperilaku sesuai dengan nilainilai kesehatan. Tujuan dari pemberian pendidikan kesehatan salah satunya yaitu untuk mengubah perilaku yang kaitannya dengan budaya. Sikap dan perilaku merupakan bagian dari budaya (Fitriani, 2011). Penelitian ini menunjukkan terdapat perubahan sikap dalam penggunaan AKDR sebelum dan sesudah diberikan pendidikan kesehatan dengan media video dan leaflet. Media dalam bentuk apapun cukup efektif dalam merubah sikap seperti halnya penelitian (Indah, Ana Puspita Indah, Indria Laksmi Gamayanti, 2016) yang menyatakan bahwa Pendidikan kesehatan dengan menggunakan media permainan ludo dan ceramah interaktif efektif meningkatkan pengetahuan, sikap dan perilaku siswa SD terhadap pencegahan adiksi permainan audiovisual elektronik.

Seluruh responden dalam penelitian ini, awalnya tidak berniat untuk menggunakan AKDR namun setelah diberikan pendidikan kesehatan dengan media video, terdapat 7 responden berniat untuk menggunakan AKDR. Sebanyak 12 responden yang tidak berniat untuk menggunakan AKDR, sebagian besar (9 responden) khawatir dengan proses 
pemasangan AKDR yang cukup rumit dan keberatan untuk memeriksa benang AKDR secara berkala.

$$
\text { Beberapa faktor yang }
$$

mempengaruhi pemilihan AKDR yaitu faktor internal dan eksternal. Faktor internal berupa pengalaman, takut efek samping AKDR, pengetahuan dan pengalaman yang salah tentang AKDR, pendidikan PUS yang rendah, malu dan risih, adanya penyakit atau kondisi tertentu yang merupakan kontraindikasi pemasangan AKDR dan persepsi tentang AKDR. Faktor eskternal berupa prosedur pemasangan AKDR yang cukup rumit, pengeruh dan pengalaman akseptor lainnya, pekerjaan, sosial budaya dan ekonomi (Marmi, 2016).

Faktor yang berupa pengalaman dan adanya penyakit atau kondisi tertentu yang merupakan kontraindikasi pemasangan AKDR bukan merupakan faktor penyebab tidak berniatnya responden dalam penelitian ini karena responden yang dipilih merupakan responden yang belum pernah menggunakan dan tidak memiliki kontraindikasi untuk menggunakan AKDR.

Teori tersebut sesuai dengan salah satu alasan terbesar responden tidak menggunakan KB AKDR yaitu khawatir dengan proses pemasangan AKDR yang cukup rumit. Prosedur medis saat pemasangan AKDR yang membutuhkan pemeriksaan pelvik sering kali menimbulkan perasaan takut selama pemasangan (Marmi, 2016). Penelitian yang dilakukan Rihardini (2015) diperoleh hasil bahwa yang faktor penghambat akseptor KB dalam memilih AKDR adalah biaya (60\%), dukungan suami (57\%), pemahaman terhadap AKDR (57\%), jumlah anak (10\%), takut terhadap alat-alat pemasangan AKDR (80\%) dan pemasangan AKDR (100\%).

Alasan terbesar lainnya yaitu keberatan untuk memeriksa benang AKDR secara berkala. Setelah menggunakan AKDR, akseptor KB AKDR diharuskan untuk memeriksa benang AKDR secara berkala (satu minggu setelah pemasangan AKDR dan setiap setelah haid) yang harus dilakukan secara benar. Hal ini menyebabkan responden merasa repot jika pada penggunaan maka responden harus secara teratur mengecek benang AKDR.

Setelah diberikan pendidikan kesehatan dengan media leaflet, sebanyak 3 responden berniat untuk menggunakan AKDR. Responden yang tidak berniat untuk menggunakan AKDR sejumlah 16 orang, sebagian besar (15 responden) merasa takut saat dimasukkan alat pada proses pemasangan AKDR.

Menurut theory of planned behavior yang disusun menggunakan asumsidasar bahwa manusia berperilaku dengan cara yang sadar dan mempertimbangkan segala informasi yang tersedia menyatakan bahwa niat seseorang untuk melakukan suatu perilaku menentukan akan dilakukan atau tidak dilakukannya perilaku tersebut. Niat melakukan atau 
tidak melakukan perilaku tertentu dipengaruhi oleh dua penentu dasar yang pertama hubungan dengan sikap ( toward behavior) dan yang lain hubungan dengan pengaruh sosial yaitu norma subjektif (subjective norms). Sikap berasal dari keyakinan terhadap perilaku (behavioral beliefs), sedangkan norma subjektif berasal dari keyakinan normatif (normative beliefs) (Ajzen, 2006).

Sikap terhadap penggunaan AKDR ditentukan oleh keyakinan mengenai konsekuensi dari penggunaan AKDR. Keyakinan berkaitan dengan penilaian subjektif individu terhadap dunia sekitarnya, pemahaman individu mengenai diri dan lingkungannya, dilakukan dengan cara menghubungkan antara penggunaan AKDR dengan berbagai manfaat atau kerugian yang mungkin diperoleh apabila individu melakukan atau tidak melakukannya. Sikap seseorang akan mempengaruhi perilakunya. Hal ini sesuai penelitian (Gonçalves, Suariyani and Suryadhi, 2014) yang menyatakan bahwa sikap ibu terhadap KB berhubungan dengan penggunaan KB di Puskesmas Comoro, Kabupaten Dili, Timor Leste

Pendidikan kesehatan yang diberikan kepada responden bertujuan untuk merubah keyakinan negatif yang dimiliki oleh responden sehingga akan merubah sikap dari setiap responden menjadi lebih baik yang ditandai dengan meningkatnya skor sikap pada seluruh responden. Setelah terjadi peningkatan sikap, diharapkan hasil bahwa responden juga akan merubah niat yang semula tidak berniat untuk menggunakan AKDR menjadi berniat untuk menggunakan AKDR. Namun, walaupun terjadi peningkatan sikap pada seluruh responden, niat responden untuk menggunakan AKDR masih sangat sedikit, yaitu 3 responden pada media leaflet. Hal tersebut terjadi karena bukan hanya sikap yang dapat mempengaruhi niat seseorang, namun terdapat norma subjektif yang dapat mempengaruhi niat.

Media video dan leaflet sama-sama efektif untuk meningkatkan sikap dalam pengguaan AKDR. Namun, selisih sebelum dan sesudah media video lebih tinggi yaitu 10,43 dibandingkan dengan media leaflet yang hanya 5,68 maka media video 4,75 lebih tinggi dibandingkan dengan media leaflet sehingga media video lebih efektif untuk meningkatkan sikap dalam penggunaan AKDR. Hal ini sesuai dengan penelitian (Sulastri, 2018) yang berjudul pengaruh pendidikan kesehatan terhadap sikap dan perilaku personal hygiene gigi dan mulut anak usia sekolah menyatakan bahwa terdapat perbedaan sikap dan perilaku personal hygiene gigi dan mulut anak usia sekolah sebelum dan sesudah diberikan pendidikan kesehatan.

Hal tersebut diperkuat dengan pernyataan (Notoatmodjo, 2012) yang menyatakan bahwa sikap merupakan reaksi atau respon yang masih tertutup dari seseorang terhadap suatu stimulus (pendidikan kesehatan) atau objek. 
Newcomb, salah seorang ahli psikologis sosial menyatakan bahwa sikap itu merupakan kesiapan atau kesediaan untuk bertindak, dan bukan merupakan pelaksanaan motif tertentu. Sikap belum merupakan suatu tindakan atau aktivitas, akan tetapi merupakan predisposisi tindakan suatu perilaku. Sikap itu masih merupakan reaksi tertutup, bukan merupakan reaksi reaksi terbuka atau tingkah laku yang terbuka

Proses pendidikan dengan melibatkan lebih banyak indera akan lebih mudah diterima dan diingat oleh para sasaran pendidikan, misalnya dengan indera pandangan-dengar akan lebih daripada indera pandang atau indera dengar saja (Suiraoka and Supariasa, 2012). Dalam penelitian ini menggunakan intervensi pemberian pendidikan kesehatan dengan media video dan media leaflet sebagai kelompok kontrol. Media video merupakan media yang menyediakan pesan audiovisual yang mengikutsertakan indra penglihatan dan pendengaran sehingga memungkinkan responden dapat menyerap lebih banyak dari materi yang diberikan. Sedangkan Leaflet merupakan selembar keras yang dilipat-dilipat, berisi tulisan cetak dan beberapa gambar tertentu tentang suatu topik khusus untuk sasaran dan tujuan tertentu (Suiraoka and Supariasa, 2012).

Berdasarkan kerucut pengalaman Edgar Dale, posisi media video lebih tinggi dibandingkan dengan media leaflet. Media video melibatkan indra penglihatan dan pendengaran, sedangkan media leaflet hanya melibatkan indra penglihatan. Lembaga riset dan penerbitan komputer, Computer Technology Research (CTR) yang menyatakan bahwa orang hanya mampu mengingat $20 \%$ dari yang dilihat, $30 \%$ dari yang didengar. Tetapi orang dapat mengingat $50 \%$ dari yang dilihat dan didengar, serta $80 \%$ dari yang dilihat, didengar dan dilakukan sekaligus. Hal ini sesuai dengan hasil penelitian ini yang menunjukkan bahwa media video yang lebih efektif untuk meningkatkan sikap dalam penggunaan AKDR (Suiraoka and Supariasa, 2012).

Responden yang berniat menggunakan AKDR setelah diberikan pendidikan kesehatan dengan media video lebih banyak dibandingkan dengan responden yang diberikan pendidikan kesehatan dengan media leaflet namun, hasil uji Chi-square untuk membedakan niat setelah diberikan pendidikan kesehatan denga media video dan leaflet menunjukkan bahwa tidak terdapat perbedaan niat dalam penggunaan AKDR setelah diberikan pendidikan kesehatan dengan media video dan leaflet ( $p$ value $>$ 0,05).

Setelah diberi pendidikan kesehatan dengan media video, terjadi peningkatan sikap pada seluruh responden, namun hal ini tidak berlaku untuk niat karena walaupun sikap dari setiap responden meningkat, tetapi masih terdapat faktor lain yang mempengaruhi niat setiap responden. Faktor-faktor 
tersebut diantaranya yaitu attitude toward the behavior (sikap), important norm (norma penting), normative beliefs (kepercayaan normatif), subjective norm (pengaruh sosial) (Jogiyanto, 2008). Faktor yang mempengaruhi niat seseorang dapat berasal dari keyakinan keperilakuan maupun keinginan meniru. Hal ini seperti yang dikemukakan oleh (Yusrina and Devy, 2016) yang menyebutkan bahwa terdapat dua faktor yang berpengaruh terhadap niat ibu untuk memberikan ASI Eksklusif di Kelurahan Magersari, Sidoarjo yaitu keyakinan berperilaku dan keinginan meniru yang dimiliki oleh ibu

Sikap adalah suatu proses penilaian yang dilakukan seseorang terhadap suatu objek atau situasi yang disertai adanya perasaan tertentu dan memberikan dasar kepada orang tertentu untuk membuat respons atau berperilaku dalam cara yang tertentu yang dipilihnya (Lestari, 2015). Important norm atau norma-norma penting atau norma-norma yang berlaku di masyarakat adalah pengaruh faktor sosial budaya yang berlaku di masyarakat dimana seseorang tinggal. Unsur-unsur sosial budaya yang dimaksud seperti kebiasaan yang sering dilakukan dapat membawa seseorang untuk mengikuti atau meninggalkan sebuah perilaku. Normative beliefs (kepercayaan normatif) merupakan keyakinan seseorang terhadap bagaimana dan apa yang dipikirkan orang-orang yang dianggap penting oleh individu dan motivasi seseorang untuk mengikuti perilaku tersebut (seberapa penting kita menerima saran atau anjuran dari orang lain). Subjective norm atau norma subjektif adalah fungsi dari keyakinan individu yang diperoleh atas pandangan orang-orang lain terhadap objek sikap yang berhubungan dengan individu (normative belief) (Jogiyanto, 2008)

Sikap masih termasuk dalam faktor yang mempengaruhi niat karena skor sikap yang didapat setiap responden setelah diberi pendidikan kesehatan tidak mencapai nilai yang maksimal. Seperti halnya penelitian (Mindianata, 2018) yang menyatakan bahwa Sikap terhadap perilaku berpengaruh terhadap niat responden untuk aktif mengikuti Posyandu Lansia. Norma-norma penting tentang KB yang ada di masyarakat, kepercayaan seseorang untuk menggunakan AKDR dari orang yang dianggap penting, dan persepsi individu terhadap harapan dari orangorang yang berpengaruh dalam kehidupan (significant others) (Jogiyanto, 2008)

\section{KESIMPULAN}

Sikap dalam penggunaan AKDR sebelum diberikan pendidikan kesehatan dengan media video didapatkan hasil ratarata 13,68 dan sikap sebelum pendidikan kesehatan dengan media leaflet yaitu 12,94. Sikap dalam penggunaan AKDR sesudah diberikan pendidikan kesehatan dengan media video mengalami kenaikan, sehingga rata-ratanya menjadi 22,31 dan pada media leaflet menjadi 18,63. 
Niat dalam penggunaan AKDR sesudah diberikan pendidikan kesehatan dengan media video yaitu terdapat 7 responden yang berniat mengguakan AKDR dan terdapat 3 responden yang berniat untuk menggunakan AKDR setelah diberikan pendidikan kesehatan dengan media leaflet.

Terdapat perbedaan peningkatan sikap dalam penggunaan AKDR sebelum dan sesudah diberikan pendidikan kesehatan dengan media video dan leaflet. Media video lebih efektif untuk meningkatkan sikap dalam penggunaan AKDR, namun tidak terdapat perbedaan niat dalam penggunaan AKDR setelah diberikan pendidikan kesehatan dengan media video dan leaflet.

Disarankan bagi responden diharapkan untuk lebih memperhatikan saat diberikan pendidikan kesehatan agar semua materi dapat diserap semaksimal mungkin sehingga dapat lebih meningkatkan sikap yang dimiliki dan akan menjadi salah satu faktor dominan dalam mengubah niat dalam penggunaan AKDR.

Bagi tenaga kesehatan terutama bidan dianjurkan dalam pemberian pendidikan kesehatan tentang kontrasepsi AKDR lebih menekankan pada hubungan seksual setelah penggunaan kontrasepsi AKDR, dan proses pemasangan AKDR secara terperinci sehingga dapat mengurangi rasa khawatir tentang AKDR yang dapat mengganggu hubungan seksual, perasaan malu dan takut saat proses pemasangan AKDR. Selain itu, dalam pemberian pendidikan kesehatan bidan dianjurkan untuk menggunakan media alternatif lain yang melibatkan lebih dari satu panca indra seperti menggunakan media video yang melibatkan indra penglihatan dan pendengaran.

\section{DAFTAR PUSTAKA}

1. Ajzen, I. (2006) 'Theory of Planned Behavior'. Available at: https://people.umass.edu/aizen/tpb.h tml.

2. BKKBN (2018) Petunjuk Teknis Penggunaan Dana Bantuan Operasional Keluarga Berencana. Jakarta: Badan Kependudukan dan Keluarga Berencana Nasional. Available at: https://www.bkkbn.go.id/pocontent/uploads/DAK-2018.pdf.

3. Dinas Kesehatan Kabupaten Temanggung (2017) Kesehatan Kabupaten Temanggung Tahun 2017. Temanggung. Available at: http://dinkes.temanggung.go.id/.

4. Febrianti, R. (2018) 'Faktor-faktor yang berhubungan dengan penggunaan IUD postplacenta', Jurnal Human Care, 3(1).

5. Fitriani, S. (2011) Promosi Kesehatan. Yogyakarta: Graha IImu.

6. Gonçalves, M. J., Suariyani, N. L. P. and Suryadhi, N. T. (2014) 'Hubungan Pengetahuan dan Sikap dengan Pemakaian Alat Kontrasepsi pada PUS di Puskesmas Comoro Dili Timor Leste', Public Health and Preventive Medicine Archive, 2(1), pp. 51-58. doi: 10.15562/phpma.v2i1.121.

7. Indah, Ana Puspita Indah, Indria Laksmi Gamayanti, R. W. (2016) 'Efektivitas Pencegahan Adiksi Video Game Menggunakan Ludo Game untuk Siswa Sekolah Dasar', Berita Kedokteran Masyarakat, 32(9), pp. 317-322.

8. Jogiyanto (2008) Sistem Informasi Keperilakuan. Yogyakarta: Andi.

9. Kementrian Kesehatan Republik 
Indonesia (2013) Buletin Jendela Data dan Informasi Kesehatan. Jakarta. Available at: http://www.depkes.go.id.

10. Lestari, T. (2015) 'Kumpulan Teori Untuk Kajian Pustaka Penelitian Kesehatan'. Yogyakarta: Nuha Medika.

11. Marmi (2016) Buku Ajar Pelayanan $K B$. Jakarta: Pustaka Pelajar.

12. Mindianata, P. (2018) 'Faktor-Faktor yang Berpengaruh terhadap Niat Keaktifan Lansia dalam Mengikuti Posyandu Lansia', Jurnal Promkes, 6(2), p. $213 . \quad$ doi: 10.20473/jpk.v6.i2.2018.213-226.

13. Notoatmodjo (2012) Promosi Kesehatan Dan Perilaku Kesehatan. Jakarta: Rineka Cipta.

14. Presiden RI (2014) 'Peraturan Pemerintah Republik Indonesia Nomor 87 Tahun 2014 tentang Perkembangan Kependudukan dan Pembangunan Keluarga, Keluarga Berencana dan Sistem Informasi Keluarga'. Jakarta: Pemerintah Republik Indonesia. Available at: http://jdih.bkkbn.go.id/public_assets/f ile/604eefdf3f08b055b67cc7c731da9 e14.pdf.

15. Rihardini,T.(2015). 'Faktor-Faktor Penghambat Akseptor Kb Dalam Menentukan Pilihan Terhadap Penggunaan Alat Kontrasepsi lud', jurnal. unipasby, 7. Available at: jurnal.unipasby.ac.id.

16. Suiraoka, I. P. and Supariasa, I. D. N. (2012) Media Pendidikan. Yogyakarta: Graha IImu.

17. Sulastri, S. (2018) 'Pengaruh Pendidikan Kesehatan terhadap Sikap dan Perilaku Personal Hygiene Gigi dan Mulut pada Anak Usia Sekolah di SD Negeri Payung', Jurnal Care, 6(1), pp. 92-101. doi: 10.33366/cr.v6i1.786.

18. Yusrina, A. and Devy, S. R. (2016) 'Faktor Yang Mempengaruhi Niat lbu Memberikan Asi Eksklusif Di Kelurahan Magersari, Sidoarjo', Jurnal Promkes, 4(1), pp. 11-21. Available at: https://ejournal.unair.ac.id/promkes/article/vi ew/5802/3711. 